\title{
A framework for mapping and monitoring human-ocean interactions in near real- time during COVID-19 and beyond
}

\author{
CA Ward-Paige, ER White, EMP Madin, GJ Osgood, LK Bailes, RL Bateman, E \\ Belonje, KV Burns, N Cullain, P Darbyshire-Jenkins, R S de Waegh, AM Eger, L Fola- \\ Matthews, BM Ford, C Gonson, CJ Honeyman, JE House, E Jacobs, LK Jordan, JJ \\ Levenson, K Lucchini, P Martí-Puig, LAH McGuire, C Meneses, PH Montoya-Maya, RA \\ Noonan, PA Ruiz-Ruiz, PE Ruy, RA Saputra, G Shedrawi, B Sing, MD Tietbohl, A \\ Twomey, DC Vergara Florez, L Yamb
}

\begin{abstract}
The human response to the COVID-19 pandemic set in motion an unprecedented shift in human activity with unknown long-term effects. The impacts in marine systems are expected to be highly dynamic at local and global scales. However, in comparison to terrestrial ecosystems, we are not well-prepared to document these changes in marine and coastal environments. The problems are two-fold: 1) manual and siloed data collection and processing, and 2) reliance on marine professionals for observation and analysis. These problems are relevant beyond the pandemic and are a barrier to understanding rapidly evolving blue economies, the impacts of climate change, and the many other changes our modern-day oceans are undergoing. The "Our Ocean in COVID-19" project, which aims to track human-ocean interactions throughout the pandemic, uses the new eOceans platform (eOceans.app) to overcome these barriers. Working at local scales, a global network of ocean scientists and citizen scientists are collaborating to monitor the ocean in near real-time. The purpose of this paper is to bring this project to the attention of the marine conservation community, researchers, and the public wanting to track changes in their area. As our team continues to grow, this project will provide important baselines and temporal patterns for ocean conservation, policy, and innovation as society transitions towards a new normal. It may also provide a proof-of-concept for real-time, collaborative ocean monitoring that breaks down silos between academia, government, and at-sea stakeholders to create a stronger and more democratic blue economy with communities more resilient to ocean and global change.
\end{abstract}

Keywords: marine ecology, pandemic, socioeconomic, climate change, anthropogenic, COVID-19

\section{Background}

The COVID-19 pandemic has affected nearly every part of the globe. A key response to the pandemic has been human confinement (e.g., restricted movement outside of homes), and business restrictions which are used to slow the spread of the outbreak 
$[1,2]$. The environmental consequences of these behaviour shifts have been both positive (e.g., reduced plane travel and thus $\mathrm{CO} 2$ emissions) and negative (e.g. increased wildlife poaching, destructive fishing, plastic pollution) [3-5]. In the ocean, the blue economy, a rapidly growing ocean-based economic sector that includes tourism, fisheries, biotechnology, aquaculture, renewable energy, and other sustainable uses [6], has been significantly impacted with tourism and maritime transport greatly decreased on multiple scales $[7,8]$. Additionally, reduced demand for fisheries products, combined with COVID-19 outbreaks among seafood workers, has led to some large reductions in commercial and small-scale fishing activity and increased recreational fishing in some areas $[9,10]$. Although the full effects of the pandemic, and associated interventions, on marine systems will not be known for many years, management and policy decisions still have to be made in the present $[2,11]$.

We are faced with a number of problems when trying to understand current socioecological change in the ocean. These barriers include: data collection is resourceintensive and often restricted to trained marine professionals, which limits the total number of observations; lack of a standardized tool for collecting and digitizing effort and observations at sea; and data are typically siloed and need to be analyzed and interpreted by experts working to answer one question at a time. These problems are amplified by the COVID-19 pandemic, which has further diminished research both by restricting travel and access to the marine environment and increasing the urgency of data collection and interpretation. Finding new ways to collect, process, analyze, and disseminate data are needed. These solutions will not only help with understanding the highly dynamic nature of the pandemic's effects, but can aid in understanding rapidly changing blue economies and the impacts of climate change. Additionally, community knowledge and acceptance of science are known to be important features in decision making [12-14], but are limited because discoveries are largely inaccessible (e.g., paywalls, technical language, lack of involvement). Therefore, integrating participatory and community science and management (e.g., citizen science) within a local context would have added benefits of improved literacy and acceptance [15-17], downstream conservation impacts [14,18], and enabling early warnings and actions that can lead to community resilience to change [19-24].

\section{Project: Our Ocean in COVID-19}

In the global project "Our Ocean in COVID-19", we aim to overcome these problems using the new eOceans platform (eOceans.co) to collaborate and collect socioecological data in real-time (Figure 1). Our international team of Principal Investigators (PIs), Field Observers, and Partner Organizations are working to document at-sea activities (fishing, surfing, beach usage, sailing, etc.) and observations (wildlife, human 
uses, anthropogenic traces) throughout the period of the pandemic and beyond. The questions we are asking include: i) What is the social value of the oceans during this global pandemic? How does it change through time and space, and can we see signs of recovery to a new 'normal'?, and ii) How are wildlife interactions and anthropogenic conditions changing through space and time?, and iii) How do these interact and can we detect thresholds that may be useful for sustainable policies and development?

\section{Project Background}

For this project, data are generated when people use the eOceans mobile app (Figure 1 ), which is an activity and observation tracker for anyone observing the ocean. Field observers are anyone near or on the ocean and they can log their activities (e.g., sailing, surfing, walking, diving) and observations of wildlife (any species) and their condition (e.g., disease), human activities, or anthropogenic traces (e.g., pollution) at any time. Principal Investigators are all trained marine scientists who oversee subprojects of the global project ("Teams" within the eOceans app). They are responsible for recruiting and working with their community to document ocean activity and observations, which are processed, analyzed, visualized by eOceans and displayed in the eOceans platform. The Principal Investigators then interpret and communicate results between communities and the global team. Partner organizations (e.g., tourism operators, NGOs) promote participation in the project within their networks.

eOceans has been crowdsourcing data around the world for independent research projects for nearly a decade and has produced scientific and policy based outcomes (Figure 2). For example, the eManta project crowdsourced data on manta raysdescribing where they are seen alive, fished, and marketed-and discovered that they were caught and sold around the world despite landings only being reported in two countries [24]. eShark Thailand and The Great Fiji Shark Count collected observations from 9,524 and 30,668 dives on 153 and 592 sites, respectively, to document baselines and spatial patterns of sharks with the goal of prioritizing local management strategies [23; Ward-Paige et al., in review]. The Global Marine Conservation Assessment crowdsourced data on shark populations (species and numbers), people's concerns for sharks, and the understanding of existing management strategies, and was used to understand the value and limitations of Shark Sanctuary policies [25]. While these projects had success, the resources required to collect and process all the data manually prevented eOceans from operating at a larger or near real-time scale. In response, a mobile app and platform was created to allow data to be recorded at-sea and to be processed, analyzed, and shared in near real-time. The Our Ocean in COVID19 project is the first to be deployed using the new platform and mobile app, which will enable us to get higher resolution information than past projects. 
Questions related to COVID-19

The impacts of COVID-19, and associated interventions, are highly complex and dynamic and capturing them in near real-time will provide a range of insights. Policies that impact human use of the ocean range from full prohibitions on people leaving their homes to no restrictions at all. Some policies have restricted ocean access and many government and conservation organizations have been unable to continue operations that include monitoring, enforcement of laws (e.g., fishing zones), and research. We have already seen examples of relaxing confinement measures, where first locals were allowed to access public spaces (e.g., beaches, marinas), with gradual increase in distance to allow for regional and national access. The timing for each stage has been highly variable at different spatial scales (e.g., county, state, country) and exceptions to this pattern are common, which makes it essential to understand the local human conditions (access to the ocean) before being able to describe the impact of human confinement on the ocean.

Three priority data products are expected from the global and regional aspects of this study. First, we will examine the spatial distribution of at-sea human activity through time. Typically, the value of the ocean to tourism or recreation is based on the number of jobs, days at sea, and dollars spent, but these are only community-wide economic metrics and do not provide at-sea resolution or social or cultural value (e.g., what part of the ocean is valued). Uniquely, the eOceans tool will enable us to understand the at-sea values and how they change through time. Figure 2 shows the sampling effort from across eOceans projects to-date (March 20,2022) and demonstrates the capacity and interest of local knowledge holders to gather and share data about the ocean, and the tool to process data which will be used to increase participation, efficiency, and transparency across communities. Similar visualizations from the eOceans app will let users develop insights for themselves about the pandemic and their own ocean use in real-time.

Second, the temporal aspect of this project is also complex. We hypothesize that human confinement policies will impact ocean uses, wildlife interactions, and anthropogenic impacts on the ocean. Hierarchical (mixed) models will allow us to explore patterns in wildlife encounters, by species or species group (e.g., whales, turtles, sharks), based on season, COVID-19 dynamics and interventions, activity type, location, distance from shore, and other regional predictors, to assess how the behaviour of both humans and wildlife has changed to influence human-wildlife interactions. Third, by giving insight into the nature of human-wildlife interactions, especially in typically populated areas, these models will help scientists predict how wildlife will respond to policy and socioeconomic developments during both this pandemic and future disturbances. 


\section{Beyond COVID-19}

In addition to providing novel perspectives and tracking the ocean towards a new normal, this project will provide insights for the future of ocean monitoring. We will evaluate and iterate new methods for real-time, at-sea collaborative human use and ecological monitoring. This in itself is an important barrier to overcome if we are to understand the full implications of human activities - positive or negative - including measuring the impact of various interventions. When combined with other data sources (e.g., oceanographic data), there is potential for new discoveries and policy actions for promoting a blue economy.

Even in its initial days, the project's inclusive design rapidly allowed intercontinental and cross-sector collaborations, including with early-career scientists [26]. These collaborations have also broken silos between scientists and other ocean explorers (people who visit the ocean professionally, recreationally, or as tourists) and allowed for two-way conversations and alliances. More broadly, real-time at-sea socio-ecological data are needed to understand the rapidly changing impact of climate change and the blue economy. These data products and collaborations may provide the insights needed to move forward more collaboratively and efficiently, enabling near real-time and transparent decisions, which could make the difference for communities to be more resilient to the impacts of climate change. While using the eOceans app enhances scientific understanding of the ecosystem, the collective teams could also inspire individuals to participate in conservation actions.

\section{Limitations}

This project faces a number of limitations. For example, the eOceans app was not available before or when the pandemic began, so true baselines are missing but previous studies in Thailand and Fiji may provide reference data for some locations. The number of contributors will continue to grow with awareness of the project and access to the ocean, so care is needed for standardization. Two effort biases include: i) the app requiring a smartphone that limits who can participate and ii) the app is currently only available in English and Spanish, with other translations possible to further increase accessibility. However, we can capture a broader perspective of users because the app user reports the observation of others who may not have smartphones (e.g., a beach walker can report surfers). There are a number of well-defined limitations of crowdsourced data [27], including in the ocean [28,29], such as those related to experience and expertise of the contributor (e.g., counting, identification), that will be considered in the analysis and interpretation of results. These data can then be combined with more traditional metrics to track the blue economy (e.g., fisheries landings). 


\section{Conclusions}

Human dependence, values, and uses of the ocean are highly complex and dynamic. Monitoring and discoveries of marine conditions have always lagged years to decades behind business, society, and ocean change, which has hindered decision making and marine management. The COVID-19 pandemic brought this barrier into the spotlight when scientists, managers, and enforcement officials could no longer study or patrol the ocean the way they did in the past. Further, the lack of tourism and access has changed the ways that people use the ocean. In this project, we are testing a new way of collecting socio-ecological data by collaborating across regions in near real-time. These efforts also highlight the importance of engaging society with science in generating knowledge on the marine environment. The more areas that can be engaged in this monitoring, the better we can understand the impact of the pandemic-and also how we can better monitor the ocean for decision making and community resilience beyond the current crisis. The purpose of this concept paper, therefore, is a call for cross-region, cross-interest, cross-sector collaboration to understand and track the blue economy in near real-time, and to help communities better understand not only how the COVID-19 pandemic has changed how the ocean is used and valued, but also to help build collaborations and protocols to mobilize collective knowledge in near real-time for informed decision making, resilient communities, and restoring ocean health. 
Figure 1. eOceans app interface for data submission and review. Data collection can be in snapshots (e.g., stationary point counts) or using track (e.g., transect, roving), where the observer logs their activity and observations of wildlife, humans (e.g., surfers, boaters, sailors), or human traces (e.g., litter, pollution, noise). A photo is included of the scene for reference. After entry, users can follow other observations in the project through the community feed.

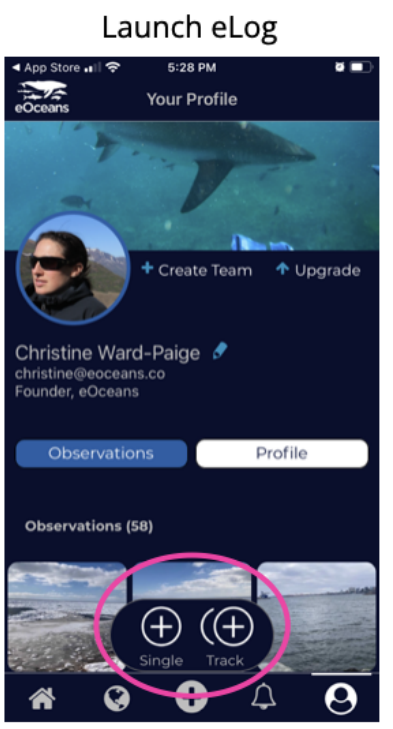

Animal Behaviours

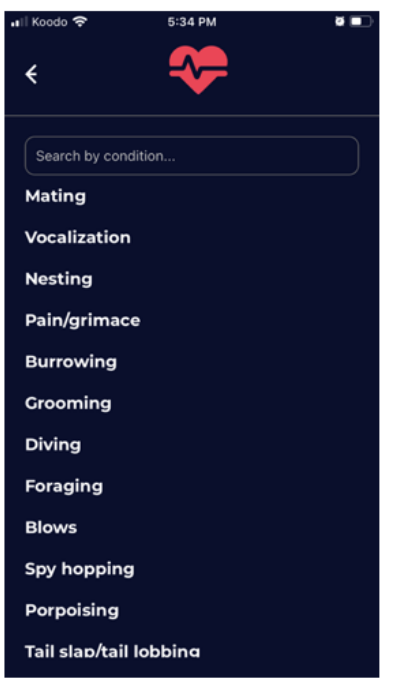

Survey Scene

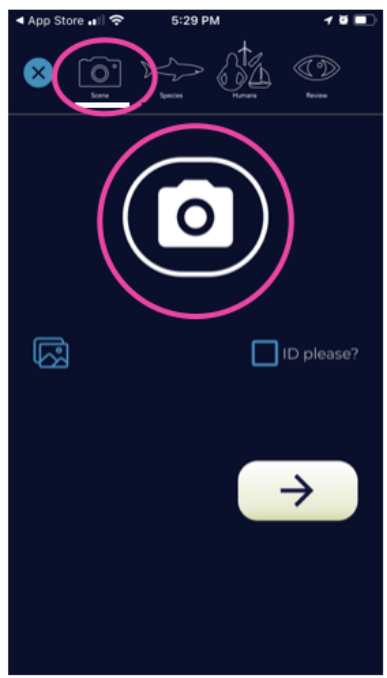

People / Pollution

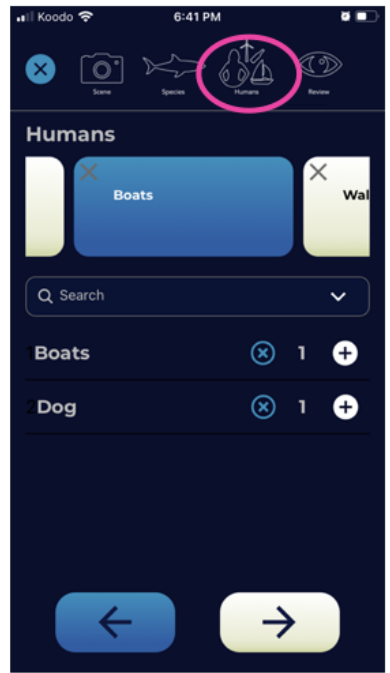

Log Wildlife

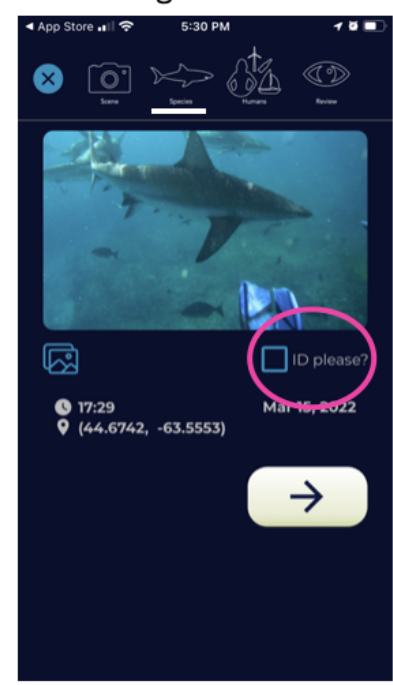

Environment

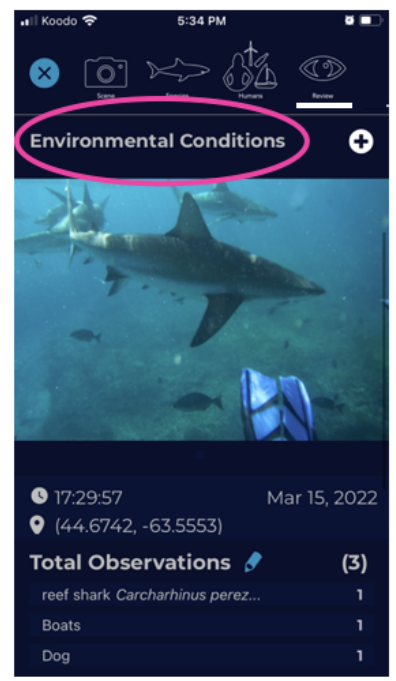

Animal Conditions

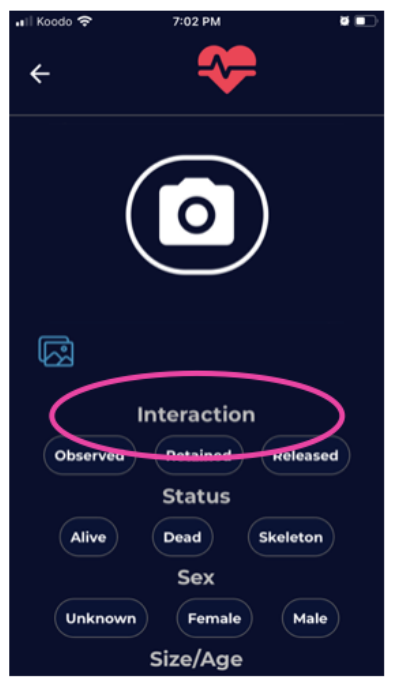

Share/Learn

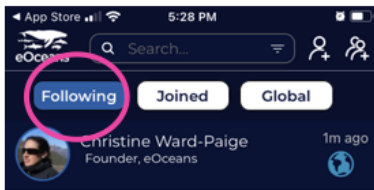

(3)

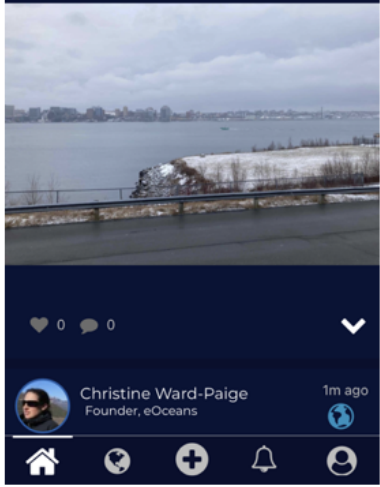


Figure 2. Distribution of effort, in number of observations (on a log scale), contributed to eOceans. Note, includes previously published data that have gone through rigorous quality control procedures. The legend shows the back-transformed number of observations at their corresponding positions on the log scale.

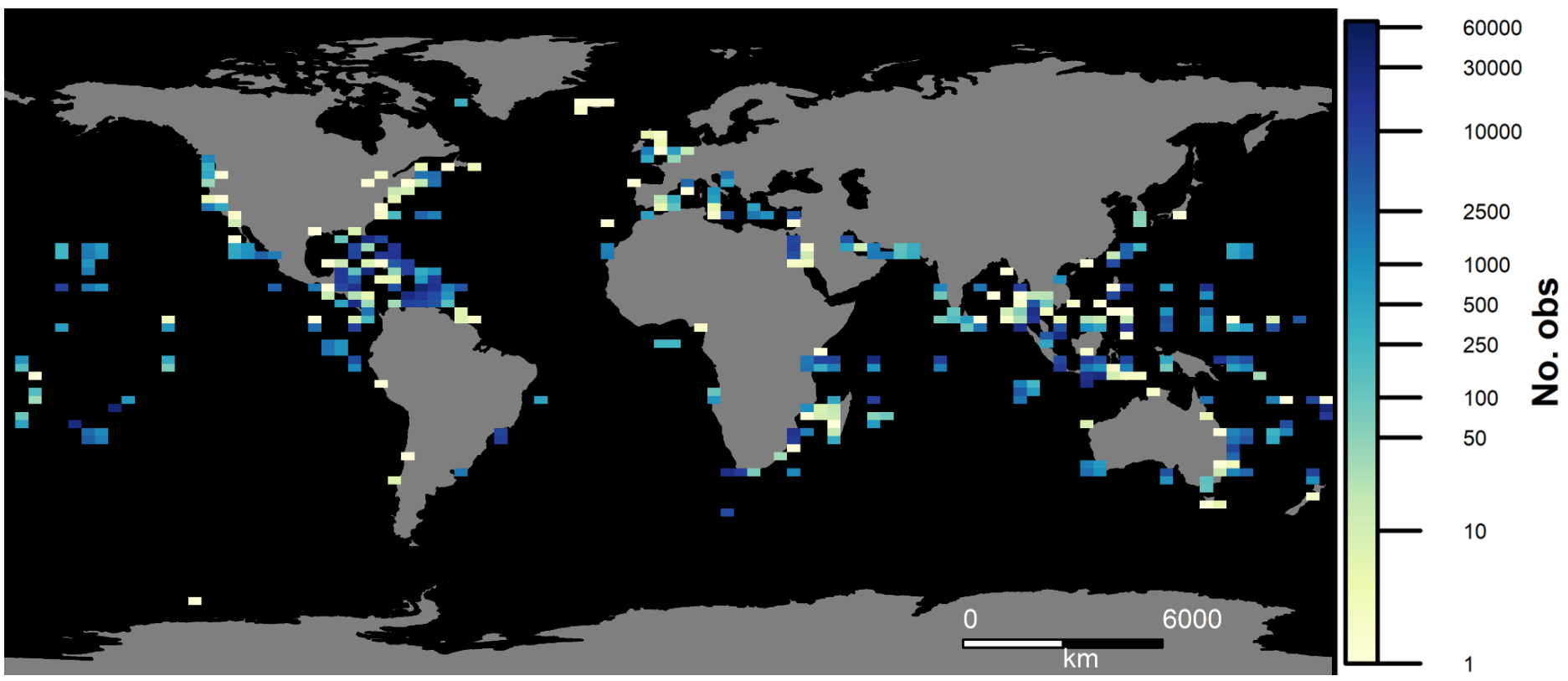


Funding: There is no funding to acknowledge at this time. eOceans is solely owned by CWP and is sponsoring the project.

Acknowledgements: This is a multi-sector project that has a wide range of collaborations. We thank all project partners including the home institutions of the principal investigators and the industry partners who are spreading the word about the project including The Moreton Bay Foundation (Australia), Live Ningaloo (Australia), Cairns Emergency Vets (Australia), Project Manaia (Austria), Calabaza Sailing Cruises (Barbados), Ocean Eyes (Chile), Chile Divers (Chile), Chile Mio (Chile), Pintarroja (Chile), Panthalassa (Chile), Centro de Buceo (Chile), Fundacion Mar y Ciencia (Chile), Ocean Missions (Iceland), Gili Shark Conservation (Indonesia), Niyama (Maldives), Gozo Azul (Mozambique), Guinjata Dive Centre (Mozambique), Tropical Research \& Conservation Centre (Nigeria), National Aquarium of New Zealand, Sustainable Ōtautahi Christchurch (New Zealand), Mar Nosso (Portugal), Canana, Pura Vida Diving (Spain), Club de Buceo (Spain), Manta Diver (Spain), Deep Ocean Diver (Spain), Thalassa Boat Tours (Thailand), Ocean Sanctuaries (US), The Adventure Boat (US), Wild Side Hawaii (US), Off The Grid Ocean Adventures (US), Pacific Marine Charters (US), Oceans Forward (US).

\section{Affiliations:}

1. CA Ward-Paige - eOceans, Halifax, NS, Canada. christine@eoceans.co

2. ER White - Department of Biological Sciences, University of New Hampshire, Durham, NH 03824 USA. easton.white@unh.edu

3. EMP Madin - Hawai'i Institute of Marine Biology, University of Hawai'i at Mānoa, Kāne'ohe, HI 96744, USA. emadin@hawaii.edu

4. GJ Osgood - eOceans, Halifax, NS, Canada. support@eoceans.co

5. LK Bailes - Biology Department, Miami University of Ohio Global Field Program, Honolulu, Hawaii, USA. laura.bailesk@gmail.com

6. RL Bateman - Murdoch University, Murdoch WA 6150, Australia. rebecca.batemanjohn@gmail.com

7. E Belonje - The Hague, The Netherlands. emilybelonje@yahoo.com

8. KV Burns - Vancouver, BC, Canada. Keanna.Burns@dal.ca

9. N Cullain - MAR Expeditions, Mozambique. nakia@zavoralab.com

10. P Darbyshire-Jenkins, Niyama Private Islands, Maldives. philippa_darbjenk888@hotmail.com

11. R S de Waegh, Auckland University of Technology, New Zealand. dw.roxy@gmail.com

12. AM Eger - Center for Marine Science and Innovation, School of Biological, Earth, and Environmental Sciences, University of New South Wales, Kengsington, NSW, Australia. aaron.eger@unsw.edu.au

13. L Fola-Matthews, Nigerian Institute for Oceanography and Marine Research, Lagos, Nigeria. larafolamatthews@gmail.com

14. BM Ford - School of Agriculture and Environment, University of Western Australia, Albany, Western Australia, Australia. ben.ford@uwa.edu.au

15. C Gonson, Geden, Clairac, France, geden.service@gmail.com

16. CJ Honeyman, Marine Science Institute, University of California, Santa Barbara, California, USA. chrishoneyman94@gmail.com

17. JE House, Research Institute for the Environment and Livelihoods, Charles Darwin University, Darwin, Australia. jenny.house@cdu.edu.au

18. E Jacobs, Keep Fin Alive, South Africa. estherjacobsKFA@gmail.com

19. LK Jordan, World Below the Waves, Auckland, New Zealand. LauraKJordan@gmail.com 
20. JJ Levenson - U.S. Department of the Interior, Bureau of Ocean Energy Management, Washington, D.C., University of Massachusetts Boston, Boston, MA, Oceans Forward, Boston, MA, USA. jlevenson@mac.comOceans

21. K Lucchini - Laboratório de Ecologia, Comportamento e Conservação, Departamento de Zoologia, Centro de Biociências, Universidade Federal de Pernambuco, Brazil. lucchini.karen@gmail.com

22. P Martí-Puig - Oceanogami, Barcelona, Spain. patricia@oceanogami.com

23. LAH McGuire, Dive!Tutukaka, Tutukaka, New Zealand. Laura.ah.mcguire@gmail.com

24. C Meneses, Ghent University, Ghent, Belgium. claudia.meneses@imbrsea.eu

25. PH Montoya-Maya - Corales de Paz, Cali, Colombia. phmontoyamaya@gmail.com

26. RA Noonan - Dalhousie University, Halifax, NS, Canada. noonanronnie@gmail.com

27. PA Ruiz-Ruiz - Ecology Department, Universidad Catolica de la Santisima Concepcion, Concepcion, Chile.pruiz@magister.ucsc.cl

28. PE Ruy - Galway-Mayo Institute of Technology, Galway, Ireland. pauleemilie.ruy@imbrsea.eu

29. RA Saputra - Indonesia Biru, West Nusa Tenggara, Indonesia. raditya.andrean@gmail.com

30. G Shedrawi - Coastal Fisheries Program, Fisheries, Aquaculture and Marine Ecosystems Division, Pacific Community, Noumea, Nouville Caledonie. georges@spc.int

31. B Sing - Shark Guardian, Nottingham, UK. brendonsing@gmail.com

32. MD Tietbohl - Red Sea Research Center, Division of Biological and Environmental Science and Engineering, King Abdullah University of Science and Technology, Thuwal, Makkah, Saudi Arabia. matthew.tietbohl@kaust.edu.sa

33. A Twomey - School of Biological Sciences, The University of Queensland, Brisbane, Queensland, 4067, Australia. a.twomey@uq.edu.au

34. DC Vergara Florez - University of Michigan, Department of Ecology \& Evolutionary Biology, Ann Arbor, MI, USA. dc.vergara10@uniandes.edu.co

35. L Yamb - Unité de Formation des Sciences de la Terre et Environnement, Université de Bordeaux, Bordeaux, France. lionel-brice.yamb@etu.u-bordeaux.fr

\section{References:}

[1] J.A. Lewnard, N.C. Lo, Scientific and ethical basis for social-distancing interventions against COVID-19, Lancet Infect. Dis. 20 (2020) 631-633.

[2] E.R. White, L. Hébert-Dufresne, State-level variation of initial COVID-19 dynamics in the United States, PLOS ONE. 15 (2020) e0240648. https://doi.org/10.1371/journal.pone.0240648.

[3] M.A. Zambrano-Monserrate, M.A. Ruano, L. Sanchez-Alcalde, Indirect effects of COVID-19 on the environment, Sci. Total Environ. 728 (2020) 138813.

[4] R.T. Corlett, R.B. Primack, V. Devictor, B. Maas, V.R. Goswami, A.E. Bates, L.P. Koh, T.J. Regan, R. Loyola, R.J. Pakeman, G.S. Cumming, A. Pidgeon, D. Johns, R. Roth, Impacts of the coronavirus pandemic on biodiversity conservation, Biol. Conserv. (2020) 108571.

[5] N.S. Diffenbaugh, C.B. Field, E.A. Appel, I.L. Azevedo, D.D. Baldocchi, M. Burke, J.A. Burney, P. Ciais, S.J. Davis, A.M. Fiore, S.M. Fletcher, T.W. Hertel, D.E. Horton, S.M. Hsiang, R.B. Jackson, X. Jin, M. Levi, D.B. Lobell, G.A. McKinley, F.C. Moore, A. Montgomery, K.C. Nadeau, D.E. Pataki, J.T. Randerson, M. Reichstein, J.L. Schnell, S.I. Seneviratne, D. Singh, A.L. Steiner, G. Wong-Parodi, The COVID-19 lockdowns: a window into the Earth System, Nature Reviews Earth \& Environment. (2020). https://doi.org/10.1038/s43017-020-0079-1.

[6] M. Vierros, C. De Fontaubert, The potential of the blue economy: increasing long-term benefits of the sustainable use of marine resources for small island developing states and 
coastal least developed countries, The World Bank, 2017.

http://documents.worldbank.org/curated/en/523151496389684076/The-potential-of-the-

blue-economy-increasing-long-term-benefits-of-the-sustainable-use-of-marine-resources-

for-small-island-developing-states-and-coastal-least-developed-countries.

[7] D. Depellegrin, M. Bastianini, A. Fadini, S. Menegon, The effects of COVID-19 induced lockdown measures on maritime settings of a coastal region, Sci. Total Environ. 740 (2020) 140123.

[8] D. March, K. Metcalfe, J. Tintoré, B. Godley, Tracking the global reduction of marine traffic during the COVID-19 pandemic, (2020). https://www.researchsquare.com/article/rs47243/latest.pdf.

[9] E.R. White, H.E. Froehlich, J.A. Gephart, R.S. Cottrell, T.A. Branch, J.K. Baum, Early effects of COVID-19 on US fisheries and seafood consumption, (2020). https://doi.org/10.1111/faf.12525

[10] E. White, J. Levine, A. Moeser, J. Sorensen, The Direct and Indirect Effects of a Global Pandemic on US Fishers and Seafood Workers, (2022). https://doi.org/10.7717/peerj.13007.

[11] H.E. Froehlich, R. Gentry, S.E. Lester, R.S. Cottrell, G. Fay, T.A. Branch, J.A. Gephart, E.R. White, J.K. Baum, Securing a sustainable future for US seafood in the wake of a global crisis, Mar. Policy. 124 (2020) 104328. https://doi.org/10.1016/j.marpol.2020.104328

[12] S. Branchini, M. Meschini, C. Covi, C. Piccinetti, F. Zaccanti, S. Goffredo, Participating in a Citizen Science Monitoring Program: Implications for Environmental Education, PLoS One. 10 (2015) e0131812.

[13] R.M. Jarvis, B. Bollard Breen, C.U. Krägeloh, D.R. Billington, Citizen science and the power of public participation in marine spatial planning, Mar. Policy. 57 (2015) 21-26.

[14] J.A. Cigliano, R. Meyer, H.L. Ballard, A. Freitag, T.B. Phillips, A. Wasser, Making marine and coastal citizen science matter, Ocean Coast. Manag. 115 (2015) 77-87.

[15] C. Cvitanovic, E.I. van Putten, A.J. Hobday, M. Mackay, R. Kelly, J. McDonald, K. Waples, $P$. Barnes, Building trust among marine protected area managers and community members through scientific research: Insights from the Ningaloo Marine Park, Australia, Mar. Policy. 93 (2018) 195-206.

[16] E.J. Theobald, A.K. Ettinger, H.K. Burgess, L.B. DeBey, N.R. Schmidt, H.E. Froehlich, C. Wagner, J. HilleRisLambers, J. Tewksbury, M.A. Harsch, J.K. Parrish, Global change and local solutions: Tapping the unrealized potential of citizen science for biodiversity research, Biol. Conserv. 181 (2015) 236-244.

[17] E. Hind-Ozan, G. Pecl, C.A. Ward-Paige, Citizen Science, Communication to the Broader Public and Trust Building, in: J.A. Cigliano, H.L. Ballard (Eds.), Citizen Science for Marine and Coastal Conservation, Taylor and Francis, 2017.

[18] J.A. Cigliano, H.L. Ballard, Citizen Science for Coastal and Marine Conservation, Routledge, 2017.

[19] S.B. Scyphers, S.P. Powers, J.L. Akins, J.M. Drymon, C.W. Martin, Z.H. Schobernd, P.J. Schofield, R.L. Shipp, T.S. Switzer, The role of citizens in detecting and responding to a rapid marine invasion, Conservation Letters. 8 (2015) 242-250.

[20] C. Roelfsema, R. Thurstan, M. Beger, C. Dudgeon, J. Loder, E. Kovacs, M. Gallo, J. Flower, K.-L. Gomez Cabrera, J. Ortiz, A. Lea, D. Kleine, A Citizen Science Approach: A Detailed Ecological Assessment of Subtropical Reefs at Point Lookout, Australia, PLoS One. 11 (2016) e0163407.

[21] M. Liboiron, F. Liboiron, E. Wells, N. Richárd, A. Zahara, C. Mather, H. Bradshaw, J. Murichi, Low plastic ingestion rate in Atlantic cod (Gadus morhua) from Newfoundland destined for human consumption collected through citizen science methods, Mar. Pollut. Bull. 113 (2016) 428-437.

[22] S. Tonin, Citizens' perspectives on marine protected areas as a governance strategy to 
effectively preserve marine ecosystem services and biodiversity, Ecosystem Services. (2018). https://www.sciencedirect.com/science/article/pii/S2212041617304606.

[23] C.A. Ward-Paige, A. Westell, B. Sing, Using eOceans diver data to describe contemporary patterns of marine animal populations: A case study of sharks in Thailand, Ocean Coast. Manag. 163 (2018) 1-10.

[24] C.A. Ward-Paige, B. Davis, B. Worm, Global Population Trends and Human Use Patterns of Manta and Mobula Rays, (2013). https://doi.org/10.1371/journal.pone.0074835.

[25] C.A. Ward-Paige, B. Worm, Global evaluation of shark sanctuaries, Glob. Environ. Change. 47 (2017) 174-189.

[26] B. Maas, K.E. Grogan, Y. Chirango, N. Harris, L.F. Liévano-Latorre, K.L. McGuire, A.C. Moore, C. Ocampo-Ariza, M.M. Palta, I. Perfecto, R.B. Primack, K. Rowell, L. Sales, R. Santos-Silva, R.A. Silva, E.J. Sterling, R.R.S. Vieira, C. Wyborn, A. Toomey, Academic leaders must support inclusive scientific communities during COVID-19, Nat Ecol Evol. 4 (2020) 997-998.

[27] C.T. Callaghan, J.J.L. Rowley, W.K. Cornwell, A.G.B. Poore, R.E. Major, Improving big citizen science data: Moving beyond haphazard sampling, PLoS Biol. 17 (2019) e3000357.

[28] C.A. Ward-Paige, J. Mills Flemming, H.K. Lotze, Overestimating fish counts by noninstantaneous visual censuses: consequences for population and community descriptions, PLoS One. 5 (2010) e11722.

[29] C.A. Ward-Paige, H.K. Lotze, Assessing the value of recreational divers for censusing elasmobranchs, PLoS One. 6 (2011) e25609. 